\title{
3 Collection-level and item-level description in the digital environment
}

\author{
Alignment of conceptual models \\ IFLA LRM and RiC-CM
}

\author{
Ana Vukadin and Tamara Štefanac
}

\section{Introduction}

Digital materials created in the course of a research project should be provided with infrastructure that supports their discovery, authenticity, accuracy, reliability and reuse. In this sense, the creation and maintenance of a research repository shares many concerns typical of archives and libraries, such as records management, information retrieval and long-term preservation. Well-known archival and library metadata practices could provide a useful framework for recording the structure and history of the repository itself, as well as for identifying individual items in the repository and linking them to similar objects of interest.

Descriptive standards and practices in archives and libraries differ on a number of levels, not least because they reflect specific business functions and legal mandates that each of these communities has in a broader social context. However, when archival and library holdings are digitised and made available on the web, their institutional context is replaced by a new environment in which boundaries between them become less distinct, while their relationships with other cultural stakeholders, including private collectors, scholars and researchers, potentially become more evident. As a consequence, the requirements for their organisation, management and description, which were once (at least to a certain point) community specific, become more and more entwined.

With this in mind, we intend to explore how harmonisation of library and archival models for resource description might enhance discovery, management and use of digitised heritage objects, but also how in turn it might affect discovery, management and use of their originals. It should be noted that this study does not research directly into users' needs and experiences of information retrieval in digital repositories. Instead, as a starting point we take the conceptual data models that underpin archival and bibliographic 
description, but in doing so we implicitly take into account user studies that were built in the models (Pisanski and Žumer 2012), as well as reflections on information behaviour in the digital environment that helped shape the structure of the models (Bailey 2013).

Conceptual data models are high-level descriptions of concepts and their relationships that are to be stored as data in an application. In a broader sense, they are abstract representations of a certain domain of knowledge or activity. The models we will be focusing on in this study are Library Reference Model (LRM), developed under the auspices of the International Federation of Library Associations and Institutions (IFLA), and Records in Contexts: A Conceptual model for Archival Description (RiC) of the International Council on Archives (ICA). Both models were designed by scholars and professionals who set up their perspectives from respective institutional and educational context, while also having greater interoperability opportunities in mind. Therefore, both models are able to express archival/bibliographical description in the form of Linked Data, which encourages data sharing and reuse in the digital environment.

To the best of our knowledge, there have yet been no attempts to align these two models, although formal representation of $\mathrm{RiC}$ is expected to be complemented with mappings between some concepts or properties in LRM ( $\mathrm{RiC}-\mathrm{O} 2021)$. We therefore hope that this research will encourage more extensive semantic and structural alignment in the future. So far, the need to achieve a certain level of interoperability between archival and bibliographic metadata has been recognised and addressed by scholars and professional bodies in numerous occasions. Many of these attempts have been motivated by large digitisation projects in the period of late 1990s and early 2000s, which will be discussed in more detail later. Willer (2015) reports on the two-way relationships between the creators of the International Standard Archive Authority Record for Corporate Bodies, Persons and Families (ISAAR(CPF)) and IFLA's working groups on the development of authority data models. IFLA's Permanent UNIMARC Committee, the body responsible for the maintenance and development of the UNIMARC data format, has been working on the specialised Guidelines for Archives in order to ensure better access to archival material held in libraries. The use of the UNIMARC format for archival description has been analysed, among others, by Zhlobinskaya (2020). International Standard Bibliographic Description (ISBD) has long been aiming to expand its scope to unpublished and archival materials, e.g., through collaboration with music cataloguers and archivists (Gentili Tedeschi 2011). Library metadata standard Resource Description \& Access (RDA) has also recently announced the intention of including archival materials, even if this expansion, similarly to ISBD, seems to be limited to items such as letters or manuscripts, and does not (yet) address more complex issues of collection-level description (Glennan 2020). 
Our research is based on two main questions: is it possible to harmonise the $\mathrm{RiC}$ and LRM conceptualisation of the information resource in order to produce a working model for multifaceted description of heritage materials, and what would be the benefits of this approach for digital humanities scholars, heritage institutions and end-users? By multifaceted description we intend the description that is able to express (and link) various aspects of described objects, such as their level of granularity (e.g., collections vs. single items), level of abstractness/physicality (content vs. carriers), provenance or mode of creation (e.g., original sets vs. "post-production" sets) and last but not least, changes that all these aspects undergo over time. We aim to demonstrate the benefits of this approach on the example of a digital repository that was created around a research project and contains diverse kinds of digitised materials (books, journals, photographs, postcards, letters, legal documents etc.), whose originals are held in various types of heritage institutions. In the search for a useful example, we were guided by Theimer's inputs regarding the relationship between archives and digital humanities: "Surveying the landscape of the digital humanities, the 'archives' that attracted my attention were primarily online groupings of digital copies of non-digital original materials, often comprised of materials (many of which are publications) located in different physical repositories or collections, purposefully selected and arranged in order to support a scholarly goal" (Theimer 2012).

In the following section we reflect on the concepts from Library and Information Sciences, Archive and Records Management Studies and Digital Humanities that have influenced the positioning of our research agenda. This is followed by the case study in which we align the semantics of the RiC entities Record Resource and Instantiation and the LRM entities Work, Expression, Manifestation and Item and investigate the possibilities of their merging into a common scheme. The scheme is then applied to a chosen number of examples from the digital repository. In the discussion section we elaborate further on the results of the study and its application in various contexts, including its implications for library and archive practices. We conclude by pointing to possible future areas of research and application.

\section{Background}

Libraries are predominantly concerned with publications, i.e., information recorded on mass-produced or otherwise widely available objects in various media. Hence, one of the principal concerns of bibliographic information organisation is establishing relationships between content and its carriers. From Panizzi's Ninety-One Cataloguing Rules to Cutter's objectives of the library catalogue, from Ranganathan's laws of librarianship to the discussions that informed the first modern international cataloguing standards (Verona 1959) and theories of bibliographic relationships 
(Wilson 1978; Tillett 1991; Leazer and Smiraglia 1999), the main function of library information tools has been to safely lead the user through the entangled forest of versions, recordings, translations, editions, impressions and transformations of works on various subjects to the particular item that will best suit her information needs. Information needs are defined through five basic user tasks that have to be supported by bibliographic data: find, identify, select, obtain, explore (Riva, LeBoeuf, and Žumer 2017, 15).

Archives also deal with records on diverse media, but these records are usually not widely available (indeed, in many cases they are unique) and are, as a rule, aggregated into sets (fonds, series, subseries etc.) based on the traditional archival principle of provenance, which requires that records should be arranged and maintained in the same order as they were originally placed by the creator (Bolfarini Tognoli, and Chaves Guimarães 2019). Archival description is thus mainly concerned with multilevel, hierarchical representations that place each record into the context of a larger unit. However, during the last few decades the conceptions of description in contemporary archival studies theory have put emphasis on broader, more dynamic, contextual information. This means that metadata should not only reflect a fond as a hierarchically structured, self-contained unit, but also point to its historical and current relationships with other fonds or collections and their members.

As more and more heritage objects of all kinds are being digitised (i.e., re-instantiated in a new medium), uploaded on the Web (i.e., published) and included in a new context that to a lesser or greater extent differs from their original environment (i.e., recontextualised), bibliographic and archival approaches to description seem to begin to converge. For example, an archival fond that has been digitised and presented on the Web will still display metadata describing circumstances of its original creation, such as names of agents or terms for business activities and functions that brought it into being. On the other hand, the fact that it is published on the Web makes it part of bibliographic universe, which means it can also be described as a publication (e.g., identified by International Standard Serial Number, which is assigned to continuing bibliographic resources such as web portals and databases). Both descriptions are "correct" and both serve a certain purpose.

There is also a third perspective, the one that aims to establish a connection between bibliographic and pre-bibliographic context. The connection, established both at the collection- and item-level, should facilitate resource discovery by creating a navigable network of originals, reproductions, editions and copies that carry the same content. At the same time, it should provide digitised items with contextual information, which falls back directly into archival and records management domain where a record is always considered within a certain context. Records can be recontextualised, but the necessity to explain the original context is a matter of transparency, and as such is firmly related to trustworthiness. 
It is needless to stress the importance of transparency, trustworthiness, accountability and ethics in the field of (digital) scholarship. This brings us to a converging point in which knowledge, standards and best practices of archival and library communities get challenged by the ideas coming from digital humanities realm. We are still facing the issues that Theimer raised almost a decade ago, when she surveyed digital humanities scholars about their concepts of the term "archive" and found them disconnected with the archivists' conceptions (Theimer 2012). For example, digital humanities do not always capture the specific value of archival knowledge which is reflected in trustworthiness of data, long-term preservation and stability of representations. However, if we attempt to produce valid and useful representations of digital collections, we will soon realise that we have entered the slippery ground where different professions and scholar disciplines each have their own understanding of the concepts that need to be captured and delivered through descriptive metadata. What is needed is a common semantic framework that will not only help integrate metadata from various sources, but also be able to explicate various metanarratives that may have affected them, considering that the act of description is always performed by a certain agent, in a certain time and place and for a certain purpose.

In our opinion, such a framework should provide: (i) the possibility of item-level description, to enable access to individual objects, (ii) distinction between content and carrier, to provide information about different physical manifestations of the same object, which might affect its accessibility, use and interpretation (Owens and Padilla 2020), (iii) the possibility of collection-level description, to capture the context within which individual objects are described, and relate it to other contexts, if they exist and (iv) the possibility of establishing relationships between described objects at all of these levels.

Similar frameworks have already been proposed, particularly in the period of the late 1990s and early 2000s, when they were largely encouraged by mass digitisation. From the <indecs $>$ project emerged the principle of functional granularity, i.e., the idea that a well-formed metadata schema should provide a way of identifying any possible part or version of the document that is required by a practical need, from a particular sentence in the document to an entire collection of documents (Rust and Bide 2000). In the UK, the Research Support Libraries Programme (RSLP) attempted to take a holistic view of library and archive activities in order to enhance access to research resources in higher education libraries (Powell, Heaney, and Dempsey 2000). From the RSLP Collection Description Project emerged $A n$ Analytical Model of Collections and their Catalogues by M. Heaney, which offered a scheme for identifying resources at the conceptual level (Content) and physical level (Item), and for linking individual Items to collections into which they had been included (Heaney 2000, 7). Last but not least, during this period the Conceptual Reference Model of International Committee 
for Documentation (CIDOC CRM) came out as the first comprehensive conceptual model originated from a professional body of a cultural heritage community. In 2006, it became an international standard for exchange of cultural information (ISO 21127).

The question of a cross-domain scheme for description of cultural heritage is therefore not new, and during the recent decades there has been more than one attempt to address it. How is, then, the harmonisation between $\mathrm{RiC}$ and LRM relevant for our purpose? The main reason is that $\mathrm{RiC}$ and LRM are the most recent models of cultural heritage information, and currently the most likely to be implemented into general descriptive standards and practices in archives and libraries. For example, LRM is implemented quite literally in RDA, which is turning into an internationally recognised standard for creating library metadata. The ISBD elements are also presently being mapped to the LRM entities. By exploring the harmonisation between LRM and RiC, we create a basis for evaluating interoperability of future descriptive practices based on LRM and RiC, which will also affect the description of digital holdings in archives and libraries. The mapping to earlier cross-domain models, especially CIDOC CRM, can further serve to verify the logical validity of $\mathrm{RiC}$ and LRM, as well as their derivative schemes. However, this is out of the scope of the present chapter (particularly taking into consideration the complexity and comprehensiveness of CIDOC CRM), and is left to future analyses both in scholarly and professional field. At the time of writing, the LRM-CIDOC CRM harmonisation is being carried out by the IFLA's Bibliographic Conceptual Models Review Group.

\section{Case study}

In this section we investigate the harmonisation between the RiC and LRM entities that represent the information resource and seek to demonstrate the applicability of the harmonised scheme on the example of the Morpurgo Topotheque. The Morpurgo Topotheque is a repository that contains digitised materials about the history of the Morpurgo bookstore, one of the oldest bookstores in Croatia, whose founder and owner was also a prominent publisher. Since the foundation in 1860 the bookstore has been operating at the same location in the historical centre of Split, within the walls of the famous Diocletian palace. In 2014 it was included in the List of Protected Cultural Heritage by the Ministry of Culture and Media of the Republic of Croatia.

The story of the Morpurgo bookstore is important for both local and national cultural history, and for this reason it was recently chosen as the subject of the doctoral thesis (later turned into a book) by the researcher Nada Topić (2017), who explored its influence on the culture of reading in Croatia. In the course of the research the author collected and digitised a variety of sources (photographs, legal documents, letters, books etc.) that served her purposes as research data. She eventually published about 
a hundred of digitised sources in an open-access repository on the Topotheque platform, which is created to support local virtual collections of European historical heritage (available at https://morpurgo.topoteka. net/). The sources published in the Morpurgo Topotheque are accompanied by minimal-level, non-standardised metadata assigned by the researcher, including title, name of the owner and keywords.

The status and history of this repository make it a good example of digital humanities practices. It clearly falls within the category of projects aiming to address the history of important cultural heritage objects (in their immovable, movable and intangible cultural dimensions) from the perspectives of humanities. The sources stored in the repository are presumed to be relevant for future research purposes. But it is important to note that, besides providing access to digitised heritage materials for future researchers, the project created an additional value - an overtly context-specific online collection of heritage materials whose physical originals are held in local and national institutions. It is context-specific because both its content and possible future use are determined by circumstances that brought it into being (a specific research agenda). For example, other researchers might have chosen a different set of resources or might have presented them differently. Anyone who might want to reuse the resources from the repository should not only be able to retrieve them, but also aware of the context for which they were aggregated, published and described.

In the rest of the section, we aim to demonstrate how a cross-domain model derived from the RiC-LRM harmonisation could enhance discovery of the content of the Morpurgo repository and to provide a better understanding of its context, but also how it might enhance discovery and interpretation of original materials held in archives, museums and libraries. We will propose a way for describing both the repository as a whole and its individual items, based on a few typical examples: (i) a digitised historic photograph representing the entrance to the Morpurgo bookstore (Ulaz u knjižaru Morpurgo), (ii) a digital image of the cover of the poetry book Zvezdane staze (Star paths) by the Croatian author Ante Cettineo, published by Morpurgo in 1923, (iii) a digital image of the front page of Knjižarstvo (Bookselling), the official journal of the Croatian Society of Booksellers in the 1920s and (iv) a digitised memo sent to the bookstore by one of the suppliers, the José Subasich Bookshop in Buenos Aires (Ponuda knjižare Jose Subasich).

\section{RiC: Record resource, instantiation}

Conceptualisation of the archival record in $\mathrm{RiC}$ revolves around the entity RiC-E02 Record Resource, defined as an information object produced or acquired and retained by one or more agents in the course of their activity. 
Record Resource has three sub-entities: RiC-E03 Record Set, RiC-E04 Record and RiC-E05 Record Part. The level at which a particular information object will be described is based on judgment in a specific context (ICA-EGAD 2019, 8).

Record is a basic independent conceptual unit that serves as the evidence of a certain activity carried out by an agent. It is the smallest unit that has its own recognisable content, structure and context and is accessible through a medium of some kind (e.g., a deed of rights, whether on paper or properly digitised). Record Set is a body of Records that are associated by categorisation and/or physical aggregation by the creator or other agent responsible for preserving the creator's records (archival fond, series etc.). Record Part is part of a Record with discrete information content that contributes to the Record's physical or intellectual completeness. An example would be a geological report with an attached map, in which the map might be considered a visually interesting document on its own, but at the same time it is a part of the record and needs to be interpreted primarily in this context.

This structure reflects a hierarchical, top-down approach to description of archival fonds and their subunits (series, subseries, dossiers etc.), which is the backbone of the General International Standard Archival Description $(\operatorname{ISAD}(\mathrm{G}))$. It arises from the aforementioned principles of provenance, according to which archival material created by a certain agent should be preserved as an inseparable whole, and organised in the same order as it was kept by the creator.

However, RiC uses the Record Set entity to broaden this traditional approach. As Popovici $(2016,26)$ notes, Record Set "[...] is intended to be an umbrella term, helping to denominate any aggregation of records and describe it accordingly to archival practices". Thus, the same Record can belong to more than one Record Set, e.g., it can be a part of the original fond held by an archival institution, but also included in a digital repository by another agent. In $\mathrm{RiC}$ (Consultation Draft 0.2 ) this is modelled with the help of the entity RiC-E06 Instantiation, which is a physical manifestation of a record, i.e., the inscription of information on a physical carrier in any persistent, recoverable form, such as a piece of paper, a video cassette or a jpeg file. Every Record Resource is instantiated at least once, but it can also have other Instantiations, whether simultaneously or over time.

\section{LRM: Work, expression, manifestation, item}

Conceptualisation of the information resource in LRM is represented by four disjunct entities that run from most abstract to most concrete: Work, Expression, Manifestation and Item. LRM-E2 Work is intellectual or artistic content of a distinct creation. It is an abstract idea in the mind of 
a creator, which is realised through LRM-E3 Expression, a distinct combination of notation, sound, image or any other type of signs (e.g., specific sentences, paragraphs, melodies or visual forms). For example, Romeo and Juliet by Shakespeare is an instance of Work, whereas its English original and Croatian translation are instances of Expressions of this Work. Sergei Prokofiev's ballet Romeo and Juliet, albeit based on Shakespeare's play, is a distinct Work, because independent intellectual or artistic effort was involved in its creation.

Every Expression of a Work can have one or more Manifestations. LRM-E4 Manifestation is a physical embodiment of an Expression. Any change concerning medium or carrier results in different physical features, and hence in a new Manifestation. For example, a digitised poster has at least two Manifestations: the original print and computer file containing its digitised image. Manifestation encompasses all physical objects (carriers) that result from the same production plan: in some cases, this includes only a single unique object (e.g., a manuscript), while in other cases it encompasses an entire set of identical copies (e.g., the 2007 edition of Romeo and Juliet by Penguin Classics). If the latter is the case, each physical exemplar of a Manifestation is a distinct LRM-E5 Item. In practice, Item represents the main source for identification and description of other three entities.

\section{The notion of information resource in RiC and LRM: Harmonisation}

Harmonisation is the combination of two or more schemes into a new scheme that may have its own structure and scope, and functions as an interoperation facilitator (Zeng 2018). It is based on the structural and, above all, semantic mapping between elements of source schemes. Structural mapping between $\mathrm{RiC}$ and LRM is facilitated by the fact that both are entity-relationship models. Semantic mapping consists of comparing meanings of their concepts. As stated by Zeng (2018), "semantic interoperability/integration is basically driven by the communication of coherent purpose. In the practice of integration and achieving interoperability, multiple contexts (including but not limited to time, spatial frame, trust, and terminology) have to be addressed".

Consistencies in meanings of the RiC and LRM entities will be compared based on their definitions, scope notes and properties presented in the models, taking into account specific domain knowledge and descriptive practices of communities within which each model was developed. In certain aspects LRM and RiC share a common view of the information resource, although with some subtle distinctions, while in other aspects they focus on entirely different features. For example, RiC models the resource according to two basic criteria: level of granularity (Record Resource and its sub-entities) and degree of abstractness/physicality (Record Resource 
vs. Instantiation). LRM models it only according to a degree of abstractness/physicality, but in a more fine-grained way, introducing four instead of RiC's two entities.

However, LRM also recognises the inherent connection between Work and Expression by stating that, even if a Work has more than one Expression, its original Expression (e.g., the original English text of Romeo and Juliet) stands out from other Expressions as the most canonical representation of the creator's intention, and therefore its attributes can also be used to describe a Work. In this sense, Work and Expression together could correspond to the entity Record Resource, and the relationship LRM-R2 Work is realized through Expression can partly be matched to some $\mathrm{RiC}$ relationships between Records, e.g., RiC-R011 Record is draft oflhas draft Record. Manifestation and Item, on the other hand, correspond to Instantiation.

$\mathrm{RiC}$ provides no possibility to distinguish between different copies of the same Instantiation, e.g., identical printed copies of a memo, because from the legal point of view each of them is original and thus represents a distinct Record Resource. LRM does not model its entities based on their level of granularity, but through the relationships LRM-R18 Work has partlis part of Work, LRM-R23 Expression has part/is part of Expression, and LRM-R26 Manifestation has part/is part of Manifestation, it provides a mechanism to organise resources hierarchically. However, this relationship is semantically restricted to the cases in which resources were conceived, realised and/or produced together as a whole and its inherent part. It does not apply to cases in which a resource is subsequently included in another resource (a collection) based on certain properties that meet the aggregator's criteria. On the other hand, $\mathrm{RiC}$ does not distinguish between a Record Set that was created as an organic whole and another that was created by accumulating already existing, independent objects. This distinction can be expressed on a more concrete level, i.e., in a concrete implementation scenario, if needed.

LRM recognises collection of objects, or more precisely a plan for collection, as a creative effort that can be identified as Work. However, its notion of collection is limited to publication context and implies a set of multiple independently created Expressions which are published together in a single Manifestation (Riva, LeBoeuf, and Žumer 2017, 93): anthologies, selections, books with independently written chapters, compilations, journals (aggregations of issues), journal issues (aggregations of articles) etc. Therefore, relationship between a collection and its members can only be established at the Expression level (LRM-R25 Expression was aggregated by/aggregated Expression). LRM is not concerned with collections of Items because they are seen as a "post-production" phenomenon which is out of scope of a bibliographic model, although Riva (2018, 27-31) makes an attempt to model bound-withs within the LRM 
framework. If Work is determined by a planned or intended activity aimed at creating something, physical collections of Items might also be regarded as Works. However, this remains to be discussed. Another option is to model a collection outside the Work-Expression-Manifestation-Item stack, simply as a sub-entity of LRM-E1 Res, which is a superclass of all the other LRM entities, whether those explicitly defined in the model or any others that are not specifically labelled (Riva, LeBoeuf, and Žumer 2017, 20).

It should be noted here that the meaning of Work/Expression is not completely equivalent to that of Record Resource. Record Resources are outcomes of an activity that may or may not be undertaken with the explicit creative plan or purpose. For example, a personal fond as a whole does not necessarily emerge from any clear plan or intention of its creator. On the other hand, a personal fond that has been digitised and made available on the web is an outcome of an intended action. As stated above, $\mathrm{RiC}$ does not distinguish between these different modes of creation, e.g., the relationship RiC-R028 accumulated by/accumulates relates "a Record Resource or an Instantiation to the Agent that accumulates it, be it intentionally (collecting) or not (receiving in the course of its activities)" (ICA-EGAD 2019, 71). Record Resource has a broader meaning than Work. Therefore, the harmonisation of these concepts will result in a hierarchical structure, in which Work and Expression are sub-entities of Record Resource.

The term record is typical for the archival community. Since a harmonised scheme should not serve only the purpose of archives, but be applicable to a wider range of heritage objects, in further text terminology will be modified so that the entity corresponding to Record Resource is called simply Resource. In the context of LRM, Resource can be expressed as a sub-entity of the top entity LRM-E1 Res. Its definition will remain that of an immaterial, intellectual object produced or acquired and retained by one or more agents in the course of their activity. If the activity in question is undertaken, or is assumed to have been undertaken, with the plan or intention to produce a distinct creation, Resource can be more precisely defined as Work. This includes planned aggregation of intellectual objects, among which a digital repository. However, Works will not include collections of Items - these are identified and described at the broader level, as Resources.

The entity Instantiation can be seen as equivalent to Manifestation. Manifestation is explicitly defined as the outcome of a certain production plan (Riva, LeBoeuf, and Žumer 2017, 25), and Instantiation, being a recording of information on a physical carrier, is also presumably always the result of a production plan. The totality of physical objects that make up a collection is therefore not regarded as Instantiation (indeed, $\mathrm{RiC}$ states that a Record Set may or may not have an instantiation). However, this may 
represent a logical obstacle if we want to describe the content of a collection separately from its various physical forms (e.g., original, microfilmed or digitised), each of which may have particular physical characteristics (e.g., extent). We therefore propose an umbrella entity (we will provisionally call it Physical object) that includes not only carriers, but also accumulated sets of carriers. It is important to bear in mind that the term physical includes digital objects as well, because they also manifest through a medium and have certain physical characteristics.

The harmonised scheme would therefore contain the following provisionally defined entities:

Resource $=$ distinct information unit created or acquired and retained by one or more agents in the course of their activity

- $\quad$ Work $=$ Resource created as a result of intended creative action

- Expression $=$ realization of Work through a distinct combination of signs (shapes, sounds, words etc.)

\section{Physical object $=$ physical embodiment of Resource}

- Instantiation/Manifestation = recording of Resource on a physical carrier in any persistent, recoverable form, according to the same production plan

- $\quad$ Item = single copy of Instantiation/Manifestation

As shown before, Record Resource in RiC already has three subentities: Record (individual level), Record Set (set level) and Record Part (component level). Instantiation is not subtype in an analogous way, presumably because it inherits the level of granularity from the respective Record Resource. However, neither in archival nor bibliographic context is this level necessarily inherited: aggregations or multipart works can be recorded on a single carrier (e.g., a collection of videos on a single CD), while single works can be recorded in multipart physical form (e.g., a novel published in two volumes). In any case, both RiC and LRM allow a concrete implementation scenario where both abstract and concrete entities will be described at any level of granularity, whether this level is inherited or not.

We can therefore model Resource and Instantiation/Manifestation as concepts or classes subdivided along two facets: one is level of granularity, and the other is a degree of abstractness/physicality. If these facets are mutually combined, the result is a scheme that is compatible with Heaney's model for collection-level description and builds on it by introducing the LRM entities as an extension for publications. The scheme is represented in Table 3.1 below, accompanied with examples from the Morpurgo repository. 


\begin{tabular}{|c|c|c|}
\hline & Individual level & Set level \\
\hline Resource & $\begin{array}{l}\text { * Comprises individual Works and } \\
\text { Expressions. }\end{array}$ & $\begin{array}{l}\text { - the Morpurgo Family Fond in the } \\
\text { State Archive in Split } \\
\text { the Heritage Collection in the Public } \\
\text { Library in Split } \\
\text { - the Photograph Collection in the City } \\
\text { Museum of Split }\end{array}$ \\
\hline Work & $\begin{array}{l}\text { - } \text { photograph The Entrance to the } \\
\text { Morpurgo Bookstore } \\
\text { - a poem from the collection Zvezdane } \\
\text { staze (Star Paths) by Ante Cettineo } \\
\text { - memo sent by the José Subasich } \\
\text { Bookstore in Buenos Aires to the } \\
\text { Morpurgo Bookstore }\end{array}$ & $\begin{array}{l}\text { the Morpurgo Topotheque digital } \\
\text { repository (aggregation of digitized } \\
\text { materials) } \\
\text { - collection of poems Zvezdane staze } \\
\text { (Star Paths) by Ante Cettineo } \\
\text { - journal Knjižarstvo (Bookselling) }\end{array}$ \\
\hline -Expression & $\begin{array}{l}\text { original black and white photograph } \\
\text { The Entrance to the Morpurgo } \\
\text { Bookstore } \\
\text { original Croatian text of a poem by } \\
\text { Ante Cettineo } \\
\text { original Croatian text of the memo } \\
\text { from the José Subasich Bookstore in } \\
\text { Buenos Aires }\end{array}$ & $\begin{array}{l}\text { Morpurgo Topotheque with text in } \\
\text { Croatian } \\
\text { Morpurgo Topotheque with text in } \\
\text { English } \\
\text { - original Croatian text of the collection } \\
\text { of poems Zvezdane staze (Star Paths) } \\
\text { text of all the articles that make up the } \\
\text { journal Knjižarstvo (Bookselling) }\end{array}$ \\
\hline Physical object & $\begin{array}{l}\text { * Comprises individual Instantiations/ } \\
\text { Manifestations and Items. }\end{array}$ & $\begin{array}{l}\text { totality of physical objects in the } \\
\text { Morpurgo Family Fond in the State } \\
\text { Archive in Split } \\
\text { totality of physical objects in the } \\
\text { Heritage Collection in the Public } \\
\text { Library in Split } \\
\text { - totality of physical objects in the } \\
\text { Photograph Collection in the City } \\
\text { Museum of Split }\end{array}$ \\
\hline
\end{tabular}

Component level

* Comprises component Works and Expressions.

- a stanza from a poem in the collection Zvezdane staze (Star Paths) by Ante Cettineo

- introductory paragraph from the memo by the José Subasich Bookstore

- original Croatian text of the stanza from a poem by Ante Cettineo

- original Croatian text of the introductory paragraph from the memo by José Subasich Bookstore

* Comprises component Instantiations/Manifestations and Items. 
Table 3.1 RiC - LRM harmonisation (Continued)

\begin{tabular}{|c|c|c|c|}
\hline & Individual level & Set level & Component level \\
\hline $\begin{array}{l}\text { Instantiation/ } \\
\text { Manifestation }\end{array}$ & $\begin{array}{l}\text { - printed black and white photograph The } \\
\text { Entrance to the Morpurgo Bookstore } \\
\text { - jpeg file with digital image of the black } \\
\text { and white photograph The Entrance to } \\
\text { the Morpurgo Bookstore } \\
\text { printed edition of the poetry collec- } \\
\text { tion Zvezdane staze in a single volume, } \\
\text { published by Morpurgo in } 1923 \\
\text { - jpeg file with digital image of the cover } \\
\text { of the } 1923 \text { edition of Zvezdane staze } \\
\text { - jpeg file with digital image of the front } \\
\text { page of journal Knjižarstvo } \\
\text { typed version of the memo by the José } \\
\text { Subasich Bookstore }\end{array}$ & $\begin{array}{l}\text { - all computer files that make up the } \\
\text { Morpurgo Topotheque } \\
\text { all computer files that make up the } \\
\text { digitized version of the } 1923 \text { edition of } \\
\text { Zvezdane staze } \\
\text { (https://digitalnezbirke.gkmm.hr/ } \\
\text { object/10148) } \\
\text { all volumes that make up the print } \\
\text { edition of the journal Knjižarstvo }\end{array}$ & $\begin{array}{l}\text { cover of the } 1923 \text { print edi- } \\
\text { tion of Zvezdane staze } \\
\text { front page of the copy of } \\
\text { the printed issue of the } \\
\text { journal Knjižarstvo, vol. } 1 \text {, } \\
\text { no. } 1(1925)\end{array}$ \\
\hline -Item & $\begin{array}{l}\text { - copy of printed black and white pho- } \\
\text { tograph The Entrance to the Morpurgo } \\
\text { Bookstore stored in the City Museum } \\
\text { of Split (HR-MGS 16378) } \\
\text { copy of jpeg file with digital image } \\
\text { of the cover of the } 1923 \text { edition of } \\
\text { Zvezdane staze, included in the } \\
\text { Morpurgo Topotheque } \\
\text { copy of memo by the José Subasich } \\
\text { Bookstore, stored in the State Archive } \\
\text { in Split within the Morpurgo Family } \\
\text { Fond }\end{array}$ & $\begin{array}{l}\text { all volumes that make up the print edi- } \\
\text { tion of the journal Knjižarstvo and are } \\
\text { stored in the National and University } \\
\text { Library in Zagreb (90.960) }\end{array}$ & $\begin{array}{l}\text { cover of the copy of the } \\
\text { printed } 1923 \text { edition of } \\
\text { Zvezdane staze, stored } \\
\text { in the Public Library in } \\
\text { Split (821.163.42-1 CET zv), } \\
\text { which was digitized for } \\
\text { Morpurgo Topotheque } \\
\text { - front page of the copy of } \\
\text { printed volume of the jour- } \\
\text { nal Knjižarstvo, vol. 1, no. } 1 \\
\text { (1925), stored in the National } \\
\text { and University Library in } \\
\text { Zagreb, which was digitized } \\
\text { for Morpurgo Topotheque }\end{array}$ \\
\hline
\end{tabular}




\section{Discussion}

The presented scheme, derived from partial harmonisation of the $\mathrm{RiC}$ and LRM, meets the requirements for cross-domain description of heritage materials listed in the Background section. It observes the principle of functional granularity by providing different levels of description, from general (Resource - Instantiation) to more fine-grained. In this way it represents a framework in which institutional policies, or particular information systems, or other extrinsic factors can determine the level of description according to specific goals and needs.

The description at the Individual and Component level facilitates finding and accessing individual objects, especially in the environment where metadata can be shared between different repositories, and links established e.g., between the description of the photograph in the City Museum in Split and the reproduction of the same photograph in a digital research repository. These links can be very precise and context-preserving if needed, thanks to the elaborate distinction between content and carriers provided by LRM entities. For example, bibliographic features of an edition can be distinguished from characteristics of a particular copy used for digitisation. A concrete physical copy of the journal (Item), characterised by evidence of its particular life cycle, can be distinguished from an "ideal" copy of the journal (Manifestation), digitised for representation from the several most preserved physical copies.

Although this provides a great support for records management, particularly in the digital environment, the level of description of individual objects is still seldom reached in archives. However, its benefits are being recognised (Higgins, Hilton, and Davis 2014) as more and more archival materials are digitised or born-digital. On the other hand, the description at the Set level ("collection-level"), typical of archives, is largely underused both in libraries and digital humanities projects (e.g., the Morpurgo Topotheque does not provide any metadata related to the collection itself). Yet describing an aggregation of objects has many advantages (Wickett 2018, 1187), whether the aggregation is an archival fond, an institutional collection, a private collection, or a repository of research data. Collection-level description reveals its importance in both physical and digital preservation and representation through several aspects: (i) the use of collection-level metadata often represents the initial step in information seeking process, as it serves as an entry point to more detailed levels of description (Heaney 2000, 3), (ii) it contextualises a collection by providing valuable information about its provenance and evolution and (iii) it documents business activity and keeps track of changes in management and use of a collection, enhancing its long-term accessibility and adaptability. If the Morpurgo repository displayed metadata about itself, instead of keeping it in the administrative technical background, the user would be provided with structured contextual information such as when, by whom 
and for what purpose the materials were collected, which might shape her understanding and use of the repository content.

Metadata could also capture changes such as augmentation of the collection by another agent. This is certainly valuable information, whether from the perspective of a repository of historic materials about a bookstore, or historical manuscripts, or medical data or any kind of collected research data. Through linkage with institutional collections that provided original material, heritage institutions would have a better insight into the use and interpretation of their holdings, which in turn might affect their decisions about collection management. These kinds of connections enhance visibility and distinctiveness of heritage institutions as holders of original materials, while also adding a layer of trustworthiness and authority to repositories derived from digital humanities projects.

Holm, Jarrick, and Scott $(2015,80)$ list digital archives as one of the research trends in digital humanities, but it seems that over the years digital humanities have scarcely addressed typical archival concerns such as authenticity and long-term preservation. Collaborative theoretical and practical researches on these matters are necessary and urgent. This is not only a matter of how both fields rise to the challenges of technological development, but foremost about how they conceive their roles in the digital world.

\section{Conclusion}

"Good cataloguing makes archival material findable and digitised facsimiles enable remote users to replicate the experience of the reading room. But the extra possibilities of the digital environment - search engine discovery, linkages across collections to related material, user arrangement and a merging of the description and digital resource - provide the user with an onward journey" (Higgins, Hilton, and Dafis 2014, 13). This implies onward journey for metadata as well. While being shared, reused, merged and integrated, metadata should still be able to express both original and transitional context in which heritage materials are created, evaluated, used and preserved.

Through partial harmonisation of archival and bibliographic conceptual data models, in this work we have underlined the advantages of cross-domain resource description for archives, libraries and digital humanities projects. We also aimed to demonstrate how multifaceted description might make digital project collections more discoverable and trustworthy from the point of view of information professionals, but also how in turn digital scholarship might enrich information provided by libraries and archives. Repositories that display digitised materials originally held in a heritage institution not only document the use of the institutional collection, but also complement it and add to its discoverability, since institutional digitisation projects are often partial and incomplete due to organisational and financial circumstances. 
Furthermore, also due to organisational and financial circumstances, it is reasonable to expect that metadata standards based on the new conceptual models will largely be tested through collaborative digital projects with other stakeholders from the cultural and educational sector. One of the most important conditions for networked collaboration is a scheme that ensures a common understanding of metadata. Heritage institutions, especially libraries, have century-long experience in creating and applying descriptive standards, as well as in adapting them to new technologies and needs (e.g., integrated access to information prompted by search engines). On the other hand, as shown by the example of the Morpurgo Topotheque, digital humanities repositories rarely provide metadata in a standardised form or use standardised metadata sets. Clear and simple guidelines based on widely accepted models and standards should help address this issue, but they have to be rooted in a common semantic framework.

While over the recent decades there have been many valuable proposals for such a framework, they are continually reviewed and improved as new disciplines, technologies and needs emerge to shape our ever-changing information environment. In this sense, future research into harmonisation of metadata models and standards could take several directions. One of them, described above, includes alignment of the new models with earlier cross-domain schemes, from simple ones such as Dublin Core (DC) to more elaborate ones such as CIDOC CRM.

Another direction could be towards user verification of the model, along the line with Pisanski and Žumer (2012) who researched user understanding of the Work-Expression-Manifestation-Item stack. However, user needs are only one, albeit essential aspect of resource description in heritage institutions; others, e.g., might include business needs. In addition, in the context of the web the notion of the "user" is sometimes fuzzy. For this reason, it is crucial that metadata schemes are "scalable" according to the principle of functional granularity, which has been explained in the Background section and demonstrated through the case study. It allows for different needs and requirements to be met at different levels of description.

In the domain of archives and libraries, the proposed descriptive framework requires reconceptualisation of the process of information management so that benefits of both collection-level description (in libraries) and item-level description (in archives) can be taken into account. The impact on research in the digital humanities domain might be in reinforcing a clear Information Science perspective (Archival and Library Studies included) that asks for setting the information landscape in an interoperable, reusable and sustainable mode. Hopefully this research will attract the attention of digital humanities scholars that share interest for information organisation and provide them with a useful insight into archival and library metadata concepts. 


\section{Bibliography}

Bailey, Jefferson. 2013. "Disrespect des Fonds: Rethinking Arrangement and Description in Born-Digital Archives." Archive Journal 1. https://www.archive journal.net/essays/disrespect-des-fonds-rethinking-arrangement-and-descriptionin-born-digital-archives/

Bolfarini Tognoli, Natália, and José AugustoChaves Guimarães. 2019. "Provenance." In ISKO Encyclopedia of Knowledge Organization, edited by Hjørland, Birger, and Claudio Gnoli. Toronto: International Society for Knowledge Organization, 2016-2021. http://www.isko.org/cyclo/provenance

Gentili Tedeschi, Massimo. 2011. "Cataloguing Commission: SubCommission on ISBD and Music.” Fontes Artis Musicae 58 (4): 391-392.

Glennan, Kathy. 2020. "Ongoing RDA Development: What's Next for the RSC?." http://www.rda-rsc.org/sites/all/files/IFLA-EURIG\%20Ongoing\%20RDA\%20 Development $\% 20 \% 281 \% 29 . p d f$

Heaney, Michael. 2000. "An Analytical Model of Collections and Their Catalogues. Third Issue, Revised." http://www.ukoln.ac.uk/metadata/rslp/model/amcc-v31.pdf

Higgins, Sarah and Christopher Hilton, and Lyn Dafis. 2014. "Archives Context and Discovery: Rethinking Arrangement and Description for the Digital Age." Girona 2014: Arxius i Industries Culturals. https://www.girona.cat/web/ica2014/ ponents/textos/id174.pdf

Holm, Poul, Arne Jarrick, and Dominic Scott. 2015. Humanities World Report 2015. London: Palgrave Macmillan. https://doi.org/10.1057/9781137500281

International Council on Archives. 1999. General International Standard Archival Description ISAD $(G)$ Second Edition. Stockholm: International Council on Archives. https://www.ica.org/sites/default/files/CBPS_2000_Guidelines_ISAD $\% 28$ G $\% 29$ _ Second-edition_EN.pdf

International Council on Archives. 2016. RiC-CM Consultation Draft v0.1. https:// escritoriopt.bn.gov.ar/pdfs/ICA-2016-Modelo\%20conceptual-RiC-0.1.pdf

International Council on Archives. 2019. RiC Consultation Draft v0.2 (preview). https://www.ica.org/sites/default/files/ric-cm-0.2_preview.pdf

Leazer, Gregory H. and Richard P. Smiraglia. 1999. "Bibliographic Families in the Library Catalog: a Qualitative Analysis and Grounded Theory." Library Records \& Technical Services 43 (4): 191-212.

Ministry of Culture and Media of the Republic of Croatia. List of Protected Cultural Heritage. https://registar.kulturnadobra.hr/\#/

Owens, Trevor John and Thomas Padilla. 2020. "Digital Sources and Digital Archives: Historical Evidence in the Digital Age." International Journal of Digital Humanities. https://doi.org/10.1007/s42803-020-00028-7

Pisanski, Jan and Maja Žumer. 2012. "User Verification of the FRBR Conceptual Model.” Journal of Documentation 68 (4): 582-592.

Popovici, Bogdan F. 2016. "Records in Context: Towards a New Level in Archival Description?" In Tehnični in Vsebinski Problemi Klasičnega in Elektronskega Arhiviranja, edited by Ivan Fras, 13-31. Maribor: Pokrajinski arhiv Maribor. http://www.pokarh-mb.si/uploaded/datoteke/Radenci/radenci_2016/013-031_ popovici_2016.pdf

Powell, Andy, Michael Heaney and Lorcan Dempsey. 2000. "RSLP Collection Description.” D-Lib Magazine 6 (9). http://www.dlib.org/dlib/september00/ powell/09powell.html 


\section{Ana Vukadin and Tamara Štefanac}

RiC-O. Next steps. 2021. https://ica-egad.github.io/RiC-O/next-steps.html

Riva, Pat, Patrick LeBoeuf, and Maja Žumer. 2017. "IFLA Library Reference Model: A Conceptual Model for Bibliographic Information. As Amended and Corrected through December 2017." https://www.ifla.org/files/assets/cataloguing/ frbr-1rm/ifla-1rm-august-2017_rev201712.pdf

Rust, Godfrey and Mark Bide. 2000. The <Indecs $>$ Metadata Framework: Principles, Model and Data. Indecs Framework Ltd. https://www.doi.org/topics/indecs/ indecs_framework_2000.pdf

Theimer, Kate. 2012. "Archives in Context and as Context." Journal of Digital Humanities 1 (2) (Spring). http://journalofdigitalhumanities.org/1-2/archives-incontext-and-as-context-by-kate-theimer

Tillett, Barbara B. 1991. "A Taxonomy of Bibliographic Relationships." Library Resources \& Technical Services 35 (2): 150-158.

Topić. Nada. 2017. Knjižara Morpurgo u Splitu (1860. - 1947.) i Razvoj Kulture Čitanja. Zagreb: Naklada Ljevak.

Topić, Nada. 2017. Knjižara Morpurgo Split. https://morpurgo.topoteka.net

Verona, Eva. 1959. "Literary unit versus bibliographic unit." Libri - International Journal of Libraries and Information Services 9 (2): 79-104.

Wickett, Karen. 2018. "A logic-based Framework for Collection/Item Metadata Relationships.” Journal of Documentation 74 (6): 1175-1189. https://doi.org/10.1108/ JD-01-2018-0017

Willer, Mirna. 2015. "Library and Archival Name Authority Data: The Possibilities for Functional Interoperability." In Records, Archives and Memory: Selected Papers from the Conference and School on Records, Archives and Memory Studies, edited by Mirna Willer, Anne J. Gilliland, and Marijana Tomić. Zadar: University of Zadar, 309-342. http://www.unizd.hr/Portals/41/elektronicka_ izdanja/RAMS_tisak_konacno.pdf?ver=2016-10-20-104937-423

Wilson, Patrick. 1978. "Two Kinds of Power: an Essay on Bibliographic control." Berkeley, CA: University of California Press.

Zeng, Marcia L. 2018. "Interoperability." In ISKO Encyclopedia of Knowledge Organization edited by Hjørland, Birger, and Claudio Gnoli. Toronto: International Society for Knowledge Organization, 2016-2021. https://www.isko. org/cyclo/interoperability

Zhlobinskaya, Olga. 2020. "Archival Description Using UNIMARC: Presidential Library Experience.” Organizacija znanja 25 (1/2). https://doi.org/10.3359/ oz2025001 